\title{
Comprehensive Petrological and Geochemical Study of Yakutian Diamonds Focussing on Re-Os Dating of Multiple Sulphides in Single Diamonds
}

\author{
D.F. Wiggers de Vries ${ }^{1}$, G.R. Davies ${ }^{1}$, D.G. Pearson ${ }^{2}$, G.P. Bulanova ${ }^{3}$, A.D. Pavlushin ${ }^{4}$, A.E. \\ Molotkov ${ }^{4}$,
}

${ }^{1}$ Faculty of Earth and Life Sciences, Vrije Universiteit, Amsterdam, The Netherlands

${ }^{2}$ Department of Earth Sciences, Durham University, United Kingdom

${ }^{3}$ Department of Earth Sciences, University of Bristol, United Kingdom

${ }^{4}$ Diamond and Precious Metal Geology Institute, Siberian Branch, Russian Academy of Sciences, Russia

Re-Os dating of sulphides has provided important information about the timing of diamond growth, particularly in Southern Africa (e.g., Pearson et al. 1998b, Pearson \& Shirey 1999, Richardson et al. 2001). To date the only sulphide inclusion ages available for diamonds for the Siberian Craton have been obtained from Os-rich sulphides of peridotitic paragenesis that, due to low $\mathrm{Re} / \mathrm{Os}$ ratios, provide relatively poor age resolution. In an attempt to better constrain the duration of individual diamond growth events within the Siberian lithosphere, we report Re-Os data from a suite of 20 Yakutian diamonds from the Mir, Udachnaya and 23rd Party Congress kimberlite pipes (Russia). The majority of the diamonds are of eclogitic paragenesis and were chosen from a suite of $>$ 6000 stones because they contain multiple sulphide inclusions (up to 15) in different growth zones giving potential constraints on diamond growth rates.

The diamonds were characterised for growth forms and subjected to photoluminescence (PL), ultraviolet (UV) and cathodoluminescence (CL) imaging. Nitrogen aggregation and content were determined by FTIR and $\delta^{13} \mathrm{C}$ studies on the host diamonds have been performed either in-situ using SIMS or by combustion of small fragments after sulphide extraction. The silicate inclusions associated with the sulphides were analysed by electron microprobe to determine if the diamonds are of P- or E-type paragenesis. PL, UV and CL imaging reveals core structures for some samples. Carbon isotopes from this suite vary from $-30 \%$ to $3 \%$ with some diamonds recording core-rim variations of up to $10 \%$.

A major goal of this work is to establish if individual diamonds record multiple growth events that are temporally resolvable. The sulphide-bearing diamonds were photographed in detail before sulphide extraction by cracking so that the geometric relationships of the inclusions inside the diamonds were clearly established. Despite the analytical challenge, individual sulphides from single diamonds are analysed to establish if sulphides represent a population formed in a single crystallisation event. Due to the different compatibility of Re \& Os this should lead to significant fractionation in $\mathrm{Re} / \mathrm{Os}$ ratios with time. The previously published data for Siberian sulphide inclusions in diamonds were for inclusions from a single diamond and give Archaean model ages ranging between 3.5 and $3.1 \mathrm{Ga}$ and a relatively poorly constrained isochron due to limited parent/daughter fractionation (Pearson et al., 1998a). Inclusion of additional samples produced an improved isochron age indicating a $3.5 \mathrm{~Gy}$ age, in agreement with the model ages (Pearson et al., 2000). The only age obtained from a Siberian E-type diamond is from Mir and it is relatively young, <582 Ma, approaching the time of kimberlite eruption at $350 \mathrm{Ma}$ (Pearson et al., 2000).

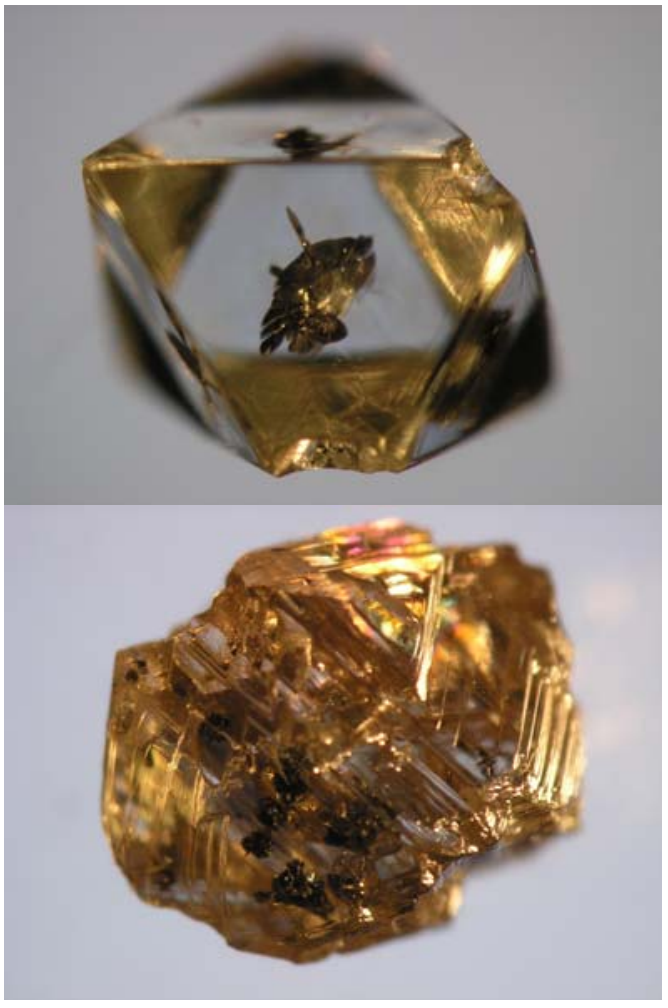

Fig. 1 Images of diamonds 4193 and 4239 of $23^{\text {rd }}$ Party Congress Pipe showing one large central sulphide (4193) and multiple sulphides near the rim of 4139. 


\section{Methods}

Sulphide inclusions in diamonds have been shown to be a complex intergrowth of monosulphide solid solution (Fe-Ni sulphides) with moderate content of $\mathrm{Ni}$, $\mathrm{Cu}$ and Mo). Laser analyses, laser sectioning or polishing could potentially sample only part of the inclusion or affect the Os content of enclosed sulphides. Hence in this study entire single sulphides were extracted from Yakutian E-type diamonds by cracking. Provided entire sulphides are obtained this approach avoids problems with potential sulphide inhomogeneity and volatile Os loss. The diamond samples under study from Mir, Udachnaya and 23rd Party Congress are in general large octahedral crystals (100-700 mg) containing multiple sulphide inclusions. To date $>30$ whole sulphides have been extracted and digested by microdistillation following the technique of Pearson et al (1998b).

\section{Results}

Carbon isotope and FTIR studies establish that there are marked variations among Yakutian eclogitic diamonds. For example four diamonds from Mir record clear CL/PL zoning and have 40-493 ppm N and up to $38 \%$ IaB aggregation. In contrast, other samples do not reveal optical zonation but record marked variations in $\mathrm{N}$ contents (215-692 ppm) and $\mathrm{N}$ aggregation (16$68 \%$ ). The latter have carbon isotope ratios in the range $-3.4 \%$ o to $-5.8 \%$, while the former have much lighter ratios; $-30 \%,-15 \%,-15 \%$ and $-17 \%$ respectively. Two crystals were studied from Udachnaya and one displays zoning in PL. They have 21-255 ppm N and up to $58 \% \mathrm{IaB}$ aggregation. The carbon isotopic range for these samples is small; $-3.4 \%$ to $-5.4 \%$. The majoritiy of the crystals from 23rd Party Congress kimberlite display zoning in UV. They have 129-784 ppm $\mathrm{N}$ and up to $28 \%$ IaB aggregation and carbon isotope ratios range between $-2.9 \%$ and $-7.0 \%$.

\section{Re-Os diamond data}

The sulphides extracted in this study ranged from 1.0$31.1 \mu \mathrm{g}$. The Yakutian eclogitic sulphides are mainly characterised by radiogenic ${ }^{187} \mathrm{Os} /{ }^{188}$ Os ratios ( 0.123 up to 5.77) and Os concentrations are low (1.8 up to 3100 $\mathrm{ppb}$ ). Re concentrations range between 6.78 and 745.5 $\mathrm{pb}$. Os and Re blanks are $10 \mathrm{fg}$ and $100 \mathrm{fg}$ respectively so that significant blank corrections are required for the smallest samples.

Fig. 2 shows the Re/Os contents of E-type sulphides from diamonds in the present study compared to data for sulphides from magmas, peridotites and peridotitic diamond inclusions. The majority of the Yakutian eclogitic sulphides plot close to a 1:1 line but a significant proportion $(\sim 10 \%)$ lie at lower Re/Os ratios suggesting significant fractionation of $\mathrm{Re} / \mathrm{Os}$ ratio during the diamond formation events.

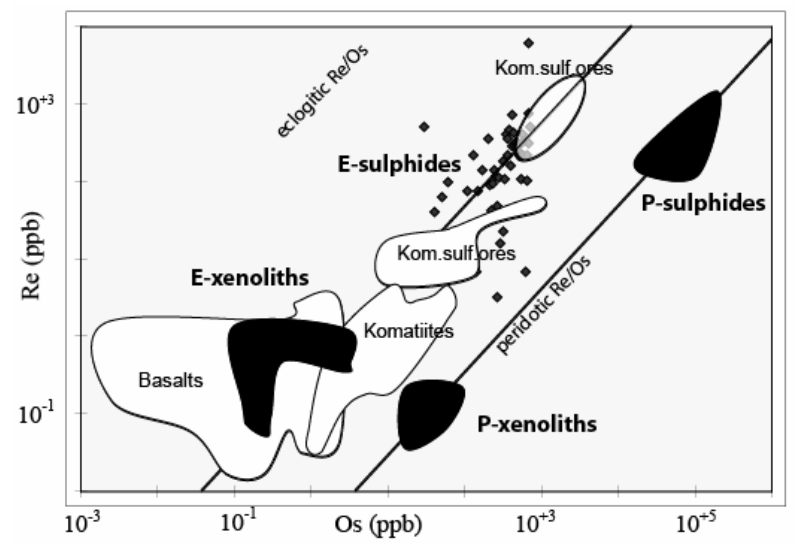

Fig. $2 \mathrm{Re} / \mathrm{Os}$ contents of sulphide diamond inclusions compared to mantle xenoliths, magmatic sulphides from oceanic basalts and komatiites after Pearson et al. (1999).

The high Re/Os ratios of the eclogitic sulphides makes them potentially extremely powerful for providing age information (e.g., Pearson et al., 1998b). This age information can be obtained either from isochronous relationships or in the form of Os model ages. $\mathrm{T}_{\mathrm{MA}}$ model ages (mantle source extraction age) are calculated from $\mathrm{Os}$ and $\mathrm{Re} / \mathrm{Os}$ ratios assuming single stage extraction from a mantle source and that since separation the sample has remained undisturbed. On their own, model ages are not reliable because of potential protogenetic inclusions and isochron relationships are preferred, given the high temperatures and fluid-rock ratios prevailing during diamond genesis, are likely to more faithfully record the time diamond formation, even in protogenetic inclusions.

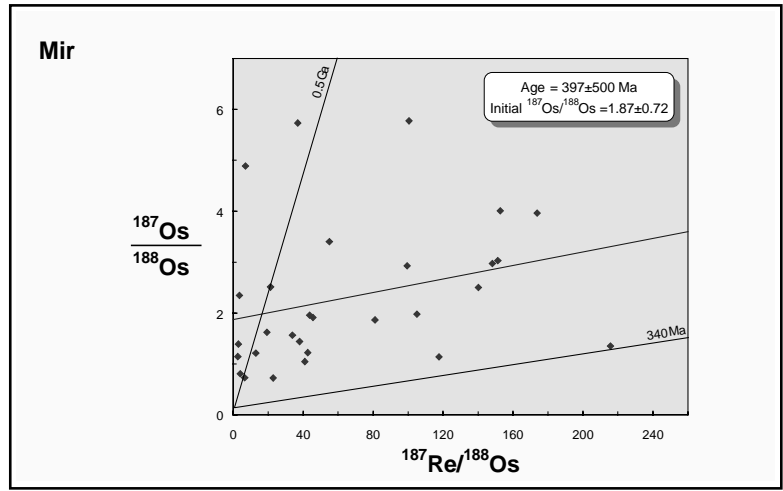

Fig. 3 Re-Os isochron diagram of sulphide inclusions obtained from Mir. $340 \mathrm{Ma}$ and 4.5 Ga reference isochrons are given for comparison.

The $\mathrm{T}_{\mathrm{MA}}$ ages from the entire Yakutian suite range from $340 \mathrm{Ma}$, close to the time of kimberlite eruption, to significantly greater than the age of the Earth (32 $\mathrm{Ga}$ ). The latter are clearly indicative that the sulphides do not record a simple two stage isotopic evolution (i.e. formed from ambient mantle). In total 6 of the sulphides have Os isotopic ratios that are unsupported by the Re they contain. This fact is most clearly displayed by sulphides from Mir (Fig. 3). Mir data all lie above a $350 \mathrm{Ma}$ reference line equivalent to 
kimberlite emplacement establishing that no samples record evidence of major Re loss and hence ages that are impossibly young. However, the data do not define a coherent isochronous relationship, producing a scatter that regresses to provide an age of $400 \pm 500 \mathrm{Ma}$ with an extremely radiogenic Os isotope initial ratio $(1.9 \pm$ 0.7). This suggests that the Mir diamonds contain more than one age population that probably had distinct initial Os isotope ratios. Sulphides from within individual Mir diamonds show similar scatter in $\mathrm{T}_{\mathrm{MA}}$ ages, independent of whether the host diamonds show optical zonation. The Mir isotope data alone do not preclude recent diamond growth, close to the time of kimberlite eruption, from fluids forming sulphides with very variable initial Os isotope ratios.

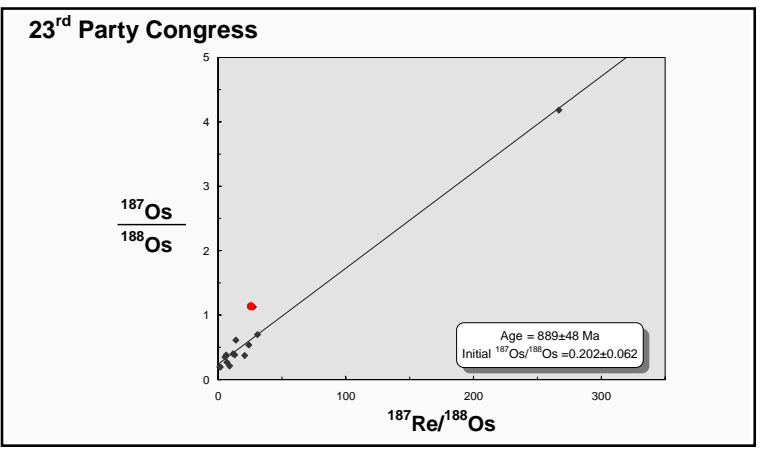

Fig. 4 Re-Os isochron diagram of sulphide inclusions obtained from $23^{\text {rd }}$ Party Congress Pipe. Red point omitted from regression, see text for details.

In contrast, sulphides from 23rd Party Congress provide far more coherent Re-Os isotope systematics (Fig. 4). The entire data set defines an age of $878 \pm 78$ Ma but omitting one data point obtained by combining multiple sub- $\mu \mathrm{g}$ sulphides significantly improves the error in the age to $898 \pm 48 \mathrm{Ma}$. The isochron age is not controlled solely by the most radiogenic point (omitting this point yields an age of $878 \pm 420 \mathrm{Ma}$ ), but it dominates the precision. The initial Os isotope ratio is $0.20 \pm 0.06$, which is more radiogenic that the subcontinental lithospheric mantle beneath this region but within error of some of the most radiogenic present day ocean island basalts (Escrig et al., 2004). Similar radiogenic initial Os isotope ratios $(0.25 \pm 0.05)$ have been reported for eclogitic diamonds from Kimberley, Venetia and Koffiefontein (Pearson et al., 1998b; Richardson et al., 2001; Richardson \& Shirey, 2008). These radiogenic values suggest that the origin of eclogitic diamonds is related to recycled oceanic crust that has been in existence long enough to produce radiogenic Os (> $50 \mathrm{Ma})$. The circa $900 \mathrm{Ma}$ diamond forming event does not correlate with any known major tectono-magmatic event in the Siberian craton nor major mantle differentiation events recorded worldwide (Pearson et al., 2007).

An in depth discussion of the data from Mir will be presented. Age populations will be discussed in relation to characteristic nitrogen aggregation state, and carbon isotopes to assess if individual diamonds record evidence for multiple crystallisation events.

\section{References}

Escrig, S., Capmans, F., Dupre, B. Allegre, C.J. 2004. Osmium isotopic constraints on the nature of the DUPAL anomaly from Indian mid-ocean-ridge basalts . Nature 431, 59-63.

Pearson, D.G., Shirey, S.B., Bulanova, G.P., Carlson, R.W., Milledge, H.J. 1998a. Dating diamonds using the Re-Os isotope technique: A study of sulphide inclusions in Siberian diamonds. International kimberlite conference, Cape Town, 7th, extended abstract, p. 661-663, Cape Town.

Pearson, D.G., Shirey, S.B., Harris, J.W., Carlson, R.W. 1998b. Sulphide inclusions in diamonds from the Koffiefontein kimberlite, S Africa: constraints on diamond ages and mantle Re-Os systematics. Earth and Planetary Science Letters, 160, 311-326.

Pearson, D.G., Shirey, S.B., Bulanova, G.P., Carlson, R.W., Milledge, H.J. 1999. Dating and paragenetic distinction of diamonds using the Re-Os isotope system: application to some Siberian diamonds. Proceedings of the VII th International Kimberlite Conference, J. J. Gurney et al., eds., 637-643.

Pearson, D.G., and Shirey, S.B. 1999. Isotopic dating of diamonds. In D. Lambert, and J. Ruiz, Eds. Economic Geological Special Publications, SEG reviews, 12, 143-171.

Pearson, D.G., Bulanova, G.P., Shirey, S.B., Carlson, R.W., Milledge, H.J., and Barashkov, Y.P. 2000. Re-Os isotope constraints on the ages of Siberian diamonds. Journal of conference abstracts 5, 776 .

Pearson, D.G., Parman, S.W. and Nowell, G.M. 2007. A link between large mantle melting events and continent growth seen in osmium isotopes. Nature 449, 202205.

Richardson, S.H., Shirey, S.B, Harris, J.W., Carlson, R.D. 2001. Archean subduction recorded by Re-Os isotopes in eclogitic sulphide inclusions in Kimberley diamonds. Earth and Plametary Scniences Letters 191, 257-266.

Richardson S. H, Shirey S.B. 2008. Continental mantle signature of Bushveld magmas and coeval diamonds. Nature 453, 910-913. 